\title{
Evaluation of Mechanical and Wear Properties of Ceramic and Inorganic compounds based Composite via PM route and Optimization through Robust design technique
}

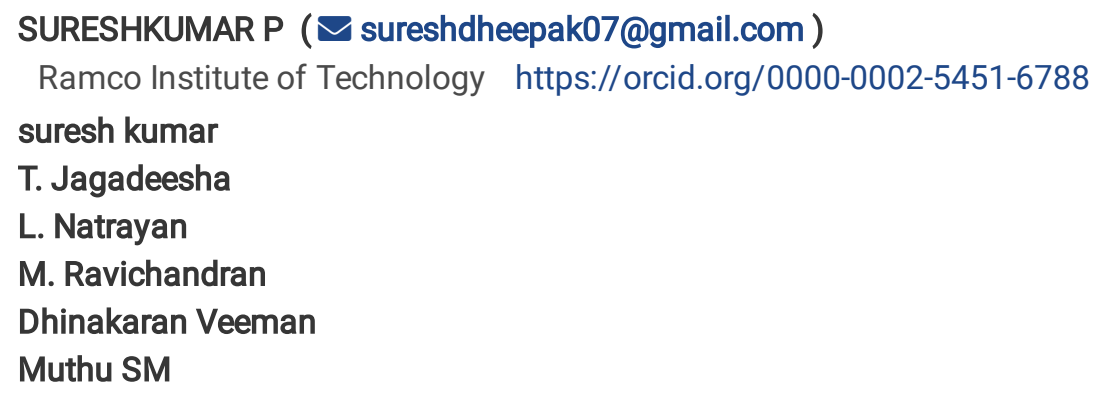

\section{Research Article}

Keywords: AA6063 alloy composite, Powder metallurgy, Hardness, Wear analysis, Inorganic reinforcement, Taguchi design of experiments

Posted Date: January 14th, 2022

DOI: https://doi.org/10.21203/rs.3.rs-1245170/v1

License: (c) (1) This work is licensed under a Creative Commons Attribution 4.0 International License. Read Full License 


\section{Abstract}

The present research study investigates the Mechanical, Physical, and Tribological properties of powder metallurgy (PM) produced AA6063 alloy reinforced with silicon nitride $\left(\mathrm{Si}_{3} \mathrm{~N}_{4}\right)$ and copper nitrate $\left(\mathrm{CuN}_{2} \mathrm{O}_{6}\right)$. Incorporation of $\mathrm{Si}_{3} \mathrm{~N}_{4} \& \mathrm{CuN}_{2} \mathrm{O}_{6}$ reinforcement in matrix material ranged from 6 to $12 \% \mathrm{Si}_{3} \mathrm{~N}_{4}$ in a 6-step interval and 2 to $6 \% \mathrm{CuN}_{2} \mathrm{O}_{6}$ in a two-step interval. The characterizations were made on the PM-produced specimens using OM, EDS, XRD, and Hardness. The reinforcement particles were uniformly distributed, which was attributed to a homogeneous mixer of matrix and reinforcements. The test findings show that as the reinforcing percentage of the ceramic and inorganic compound increases, properties such as hardness and density rise considerably and monolithically. The existence of phases such as $\mathrm{Si}_{3} \mathrm{~N}_{4}$ and $\mathrm{CuN}_{2} \mathrm{O}_{6}$ reinforcement in the AA6063 matrix was ensured by $\mathrm{X}$-ray diffraction. The hardness of $\mathrm{AA} 6063 / 12 \% \mathrm{Si}_{3} \mathrm{~N}_{4} / 6 \% \mathrm{CuN}_{2} \mathrm{O}_{6}$ increased by $88 \%$ over the base alloy due to a mismatch in thermal expansion between the Al matrix and reinforcement, which causes massive internal stress, causing the aluminium matrix to plastically deform to accommodate the reduced volume expansion of $\mathrm{Si}_{3} \mathrm{~N}_{4}$ and $\mathrm{CuN}_{2} \mathrm{O}_{6}$ particles. The dry sliding wear test was determined using the Pin-on-Disc method, and the results show that the composite is more wear-resistant. An orthogonal array and analysis of variance were utilized to evaluate the solution, including parameters using the Taguchi robust design technique. The weight percentage of the $\mathrm{Si}_{3} \mathrm{~N}_{4} / \mathrm{CuN}_{2} \mathrm{O}_{6}$ compound and the relationship between weight \% of reinforcement and applied load had the most significant impact on composite wear resistance. The produced composite's wear morphology was studied using images from a scanning electron microscope and energy dispersive spectroscopy.

\section{Introduction}

The use of Hybrid Aluminum matrix composite (HAMC) has increased recently due to its applications in the fields such as aerospace, marine, automobile, and lightweight components. Because of their beneficial properties like good strength to weight ratio. To fabricate lightweight $\mathrm{Al}$ and $\mathrm{Mg}$ components, traditional production techniques such as solid-state processing (Powder Metallurgy (PM)) and liquid metallurgy (casting) and are frequently used. Due to environmental conditions, speed, and mechanical loading, these lightweight Industrial components are prone to wear. Material loss happens in parts due to repeated rubbing operations, potentially increasing maintenance costs and repair time. The best way to enhance its tribological and mechanical properties of hybrid aluminum composite has been attained through ceramic reinforcement such as $\mathrm{SiC}[1,2], \mathrm{B}_{4} \mathrm{C}[3,4], \mathrm{Al}_{2} \mathrm{O}_{3}[5,6]$, $\operatorname{TiC}[7,8]$, and AIN $[9,10]$. Microstructural properties such as shape, reinforcing distribution, volume fraction, quantity, and particle size influences the wear performance of the MMCs. Many researchers have sought to produce MMC pieces with various reinforcements to increase their strength. Aravindan et al. [11] mixed $10 \mathrm{wt} \%$ of SiC with Al6063 and discovered that there is an increase in properties such as Percentage (\%) Elongation, Yield Strength, Ultimate Tensile Strength (UTS) because of increasing the

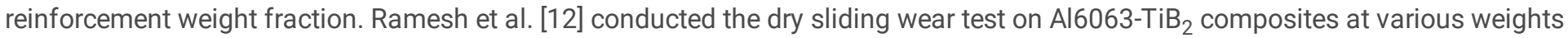
and sliding velocities. They reported that the composite exhibits a lower wear rate and coefficient of friction (COF) than the Al6063 alloy. Nonetheless, when applying the weight, the sliding velocity increased, the wear rates appeared to increase.

The liquid metallurgy processed AA6063 - 10\% $\mathrm{Si}_{3} \mathrm{~N}_{4}$ reinforced composite has given an 86 percent increase in hardness compared to the base alloy, according to Veereshkumar et al. [13]. Basavarajappa et al. [14] found that increasing ceramic and metallic reinforcement and changeover load from moderate to severe wear improved composite wear resistance. Hossein Abdizadeh et al. [15] discussed the aluminum composite reinforced with $\mathrm{ZrSiO}_{4}$. It is noticed that compressive strength and yield stress change when

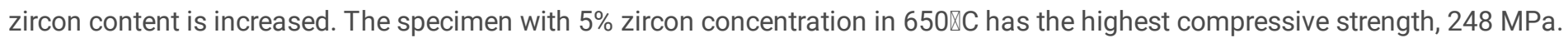
Because of preventing plastic deformation and causing more significant strain hardening. Erdemir et al. [16] investigated the mechanical characteristics of Al2024/SiC composites revealed that raising the $\mathrm{SiC}$ content to $30 \%$ and $40 \%$ enhanced microhardness, but growth in the $\mathrm{SiC}$ content to greater than $50 \%$ and $60 \%$ reduced microhardness due to high porosity. The mechanical properties of the $\mathrm{Al}-\mathrm{TiO}_{2}$ powder metallurgy composites were examined by Ravichandran et al. [16]. According to the findings, adding $5 \%, \mathrm{TiO}_{2}$ increases tensile strength while adding $7.5 \% \mathrm{TiO}_{2}$ increases hardness. Using powder metallurgy, Fathy et al. [17] studied the Al matrix composites reinforced with 5, 10, and 15\% iron powder which have good mechanical and magnetic properties. As a result of the Fe powders' dispersion strengthening the Al matrix and the creation of intermetallic compounds as a mass percentage of the Fe powders. 15 percent iron powder had strength in compression of $550 \mathrm{MPa}$ and a plastic strain of 65

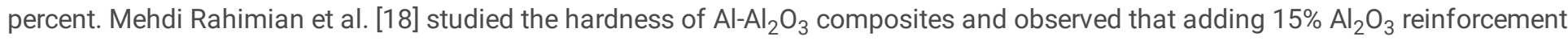


increases hardness. They reported that the added ceramic particle improved the properties of aluminum composites. The ceramic and non-ceramic reinforcements have been raised the properties of aluminium composite.

Pal et al. [19] examined Al reinforced with a different weight percentage of $\mathrm{Ni}$ ranging from $10-40 \%$. It is found that the tensile strength, hardness, and thermal conductivity of Al matrix composite reinforced with $20 \%$ carbon fiber increases by adding Ni. Raj et al. [20] investigated the tribotest properties of an aluminium $\mathrm{LM} 13 / 12 \% \mathrm{Si}_{3} \mathrm{~N}_{4} / 3 \% \mathrm{Gr}$ composite fabricated by stir casting technique. Lotfy et al. [21] used a stir casting method to make $5 \%$ aluminium BN/Si3N4 with Cu alloy reinforcement. They reported that the impact of the BN/Si3N4 reinforcement on the microstructure, thermal and mechanical properties. Sharma et al. [22] investigated the effects of $\mathrm{Si}_{3} \mathrm{~N}_{4}$ on $\mathrm{AA6082} / \mathrm{Si}_{3} \mathrm{~N}_{4}$ composite on the wear behavior.

This research aims to make an $\mathrm{AA6063} / \mathrm{Si}_{3} \mathrm{~N}_{4} / \mathrm{CuN}_{2} \mathrm{O}_{6}$ composite using a stir casting method and investigate the influence of $\mathrm{Si}_{3} \mathrm{~N}_{4}$ reinforcement on the mechanical and tribological characteristics of AMCs. The produced composite was characterized using OM and XRD to examine the structure and phases. On the other hand, the Taguchi technique has been shown by researchers to be an effective tool for composite wear study [23-28]. The main goal of this study was to manufacture the hybrid aluminium matrix (HAM) composites (ceramic and inorganic reinforcement) using powder metallurgy (PM) and analyze their tribological and mechanical properties. Furthermore, Taguchi's design of experiments was used to study the effect of sliding distance, applied stress, and sliding speed on the wear behavior of hybrid composites. The proportion of influence of several parameters and their relation was determined using analysis of variance. EDS and SEM morphology of the worn surfaces were studied to understand the better wear mechanisms.

\section{Experimental Work}

\subsection{Materials and Methods}

The powder metallurgy (PM) method was employed to fabricate the hybrid aluminium matrix (HAM) composites. The matrix used in this study was aluminium 6063, and the composition is described in the Table. 1. In this analysis, inorganic metallic reinforcement $\mathrm{CuN}_{2} \mathrm{O}_{6}$ and ceramic $\mathrm{Si}_{3} \mathrm{~N}_{4}$ were used as the reinforcements, as shown in Table. 2. The matrix powder was purchased by M/s Metal Powder Company Ltd., Tamilnadu, India. The reinforcement powders were obtained from Isochem Laboratories, Kochi. Four combinations of nitrate-based inorganic element and ceramic-based element aluminium composites were prepared for the mechanical property analysis. For tribological studies, three varieties of the mixture were used.

The Al elemental powders were dried in a muffle furnace at $100^{\circ} \mathrm{C}$ for one hour. A planetary tumbler mixer was used to mix the powder containing $10 \mathrm{~mm}$ diameter stainless steel balls. The ball to powder weight ratio of 15:1 was maintained up to 4 hours mixing time to ensure uniform mixing and reduce the powder size. The Al elemental powders were dried in a muffle furnace at $100^{\circ} \mathrm{C}$ for one hour. Mixing was done at $250 \mathrm{rpm}$ with toluene to avoid oxidation. AA6063 powder mixed with different weight fractions of silicon nitride ( 6 and $12 \mathrm{wt} . \%$ ) and copper nitrate (2 and $4 \mathrm{wt} . \%$ ) in a tumbler mixer. The green compacts were prepared by the mixed powder pressed at $750 \mathrm{MPa}$ in a compression-testing machine (CTM). Fig.1 depicts the composite preparation technique. The green compacts were sintered at $520^{\circ}$ for 1 hour at a steady temperature. The sintered composite was solution treated in a furnace at $530^{\circ} \mathrm{C}$ for 2 hours and then water quenched before being naturally aged for 72 hours.

\subsection{Characterization}

The density of the AA6063 matrix composite specimens was calculated using the Archimedean standard. The samples were immersed in distilled water for density calculations. The specimen's weights were measured before and after immersion. The microstructure of the $\mathrm{AA} 6063 / \mathrm{Si}_{3} \mathrm{~N}_{4} / \mathrm{CuN}_{2} \mathrm{O}_{6}$ composite generated by powder metallurgy was investigated. On the PM manufactured composites, sectioning was done, and then a standard metallographic study was used to achieve the mirror finish. The samples were ground with $\mathrm{SiC}$ sheets from 400 to 1500 grits, then polished with an alumina velvet cloth to achieve a finish similar to a mirror. The samples were etched with Keller's $\left(\mathrm{HCl}+\mathrm{HNO}_{3}+\mathrm{HF}\right)$ etchant to reveal the microstructure. The structure and distribution of the reinforcement were analyzed using an optical microscope (OM). The phase's presence on the PM composite specimens was identified using an X-ray diffractometer (Bruker D8 Discover). The hardness of the composites was determined using a Rockwell hardness tester following ASTM E10 to understand the impact of adding reinforcement to the matrix. A spherical 
hardened steel ball indenter with a diameter of $10 \mathrm{~mm}$ was used for made indentation. A $500 \mathrm{gf}$ load was applied, and a dwell time was maintained for $15 \mathrm{sec}$. The hardness experiment was carried out in ten different locations then the average value was taken.

\subsection{Wear test}

The wear characteristics of the composites were measured using a pin-on-disc test based on the ASTM G99 standard under dry sliding conditions. A combination of reinforcement $\left(\mathrm{Si}_{3} \mathrm{~N}_{4}+\mathrm{CuN}_{2} \mathrm{O}_{6}\right)$, sliding speed, sliding distance, and load was explored as wear parameters. The photograph of the Pin-on-Disc wear test setup is shown in Fig. 2. The sliding disc with an HRC 65 and a diameter of $165 \mathrm{~mm}$ is made using EN32 steel. The sliding pin is used as a test specimen with a diameter of $10 \mathrm{~mm}$ and a height of $25 \mathrm{~mm}$. The test sample and the pin contact surfaces were polished and flattened using SiC sheets before the wear test.

In order to reduce the stress of hard and soft ductile matrix material, the test specimen was manually prepared by grinding the composite aluminum surface with the range of 240-2000 grit silicon carbide papers. The surface is then polished with alumina using a disc polishing machine. Acetone was used for cleaning the counter face disc after each test. The wear loss can be calculated by measuring the weight of the specimens before and after the test, with an accuracy of $0.1 \mathrm{mg}$. Each test was repeated five times, with the average value being used to analyze the results. A scanning electron microscope (SEM) was used to examine the worn surface on the wear track. The following parameters were considered during the wear test: (i) sliding distance, (ii) reinforcing weight percentage, (iii) sliding speed and (iv) applied load.

\subsection{Robust Design Technique}

The Taguchi technique is an optimization tool that helps determine optimal parameters in a straightforward, quick, and systematic manner. Compared to traditional experimentation, this technique significantly decreases the number of experiments needed to shape response functions. One-variable-at-a-time tests, in which one variable changes when the others remain constant, are common in traditional experimentation. The main drawback of this method is that it ignores any potential interactions between the parameters. It is noticed that when one element fails to have the same influence on the response of another factor at various levels, an interaction occurs. The response function's average value at a given level of a parameter is the principal output. The departure a factor level creates from the cumulative mean response is its effect. The Taguchi methodology is used to optimize processes and find the best combinations of elements reactions. The signal-to-noise $(\mathrm{S} / \mathrm{N})$ ratio is calculated from the experimental data. Depending on the sort of characteristics, different $\mathrm{S} / \mathrm{N}$ ratios are available. Smaller $\mathrm{S} / \mathrm{N}$ ratios are better, greater $\mathrm{S} / \mathrm{N}$ ratios are better, and nominal $\mathrm{S} / \mathrm{N}$ ratios are better. The smaller-is-better rule applies to the $\mathrm{S} / \mathrm{N}$ ratio for the least wear loss. The $\mathrm{S} / \mathrm{N}$ ratio is a logarithmic ratio that can be determined, as seen below, the transformation of the loss function.

$$
\frac{S}{N}=-10 \log \frac{1}{n}\left(\varepsilon_{y^{2}}\right)
$$

$\mathrm{n}=$ repeated number of trials

$y=$ response the sliding wear characteristics

Table. 3 shows the three levels of investigation for the four process parameters. Table. 4 displays the design of experiments of parameters used for the wear study.

\section{Result And Discussion}

\subsection{Density}

Theoretical densities for various base compositions to reinforcement added composite were determined using the law of mixtures, whereas practical densities were determined using the Archimedes principle. Theoretical and practical density values were determined, and the graph is depicted in Fig. 3. The theoretical density exhibits a high-density value than the practical density. The percentage of $\mathrm{Si}_{3} \mathrm{~N}_{4}$ in the AA6063- $\mathrm{Si}_{3} \mathrm{~N}_{4}$ composite grows from 0 to $12 \mathrm{wt} \%$. The density of the material increased by $2.42 \%$ compared to AA6063-12 \% $\mathrm{Si}_{3} \mathrm{~N}_{4}$; adding $4 \% \mathrm{CuN}_{2} \mathrm{O}_{6}$ increased the density value by $1.57 \%$. The higher density of AA6063 composite 
is due to $\mathrm{Si}_{3} \mathrm{~N}_{4}$ and $\mathrm{CuN}_{2} \mathrm{O}_{6}$ addition, which raised the density and filled the void space. As the density of the composite grows, its mechanical properties improved [29].

\subsection{Optical Microscope analysis}

Fig. 4 a-d shows the optical micrograph of the Al6063-12\% $\mathrm{Si}_{3} \mathrm{~N}_{4}-\left(2\right.$ and $4 \%$ of $\mathrm{CuN}_{2} \mathrm{O}_{6}$ MMCs fabricated by the PM technique. The white area depicts the $\mathrm{Si}_{3} \mathrm{~N}_{4}$ particles, while the black area depicts the $\mathrm{CuN}_{2} \mathrm{O}_{6}$ particles. It is elucidated from OM pictures that the reinforcing particles in the $\mathrm{Al} 6063$ alloy were dispersed equally. The micrograph depicts the increase in CuN $\mathrm{O}_{6}$ content distribution in MMCs. The propensity reaction and the alloying materials utilized in the processing are responsible for the good bonding observed between the reinforcement and the matrix. Strong interfacial bonding was developed in the fabricated composites during the sintering process due to the chemical reaction between the matrix and reinforcement. There are no cracks, and micropores were found in the MMCs, always increasing the density and hardness of the composites by the existence of reinforcement particles. The absence of agglomerations in the composites can be attributed to the uniform distribution of reinforcement particles. The formation of unnecessary intermetallic compounds was indeed minimal due to low sintering temperature and short time.

\subsection{XRD analysis}

Fig. 5 shows the XRD patterns of the $\mathrm{AA} 6063 / \mathrm{Si}_{3} \mathrm{~N}_{4} / \mathrm{CuN}_{2} \mathrm{O}_{6}$ composites reinforced with $\mathrm{Si}_{3} \mathrm{~N}_{4}$ and 2 , 4, and $6 \%$ CuN $\mathrm{O}_{6}$ particles as developed by PM revealed that the presence of metallic compounds $\mathrm{Al}, \mathrm{Cu}, \mathrm{Si}_{3} \mathrm{~N}_{4}$, and $\mathrm{CuN}_{2} \mathrm{O}_{6}$ particles. The composite of AA6063/ $\mathrm{Si}_{3} \mathrm{~N}_{4} / 2 \% \mathrm{CuN}_{2} \mathrm{O}_{6}$ has high Al and $\mathrm{Si}_{3} \mathrm{~N}_{4}$ peaks and weak $\mathrm{CuN}_{2} \mathrm{O}_{6}$ peaks, as seen in the XRD patterns. It's because there are fewer $\mathrm{CuN}_{2} \mathrm{O}_{6}$ particles in the mix. When the amount of $\mathrm{CuN}_{2} \mathrm{O}_{6}$ was added at 4 and 6 wt. $\%$, significant peaks of $\mathrm{CuN}_{2} \mathrm{O}_{6}$ were observed.

\subsection{Hardness}

The hardness test was carried out on the specimens measuring 10mm in length and 10mm in diameter, per the ASTM E10-07a standards under room temperature circumstances. The test was conducted on AA6063 composites with a different weight percentage of ceramic and inorganic compound reinforcement. Each value is based on a five-reading average. Fig. 6 shows the outcomes of the test on the given specimen. It is confirmed from the hardness plot that the composites' hardness is substantially more than the base alloy's. The hardness of the material increases as the reinforcing weight percent increases. The overall hardness of the composite increases because of the higher hardness of $\mathrm{Si}_{3} \mathrm{~N}_{4}$.

Further, increase the hardness of composite by adding inorganic reinforcement of $\mathrm{CuN}_{2} \mathrm{O}_{6}$. Because of the reinforcement particles absorbed into the aluminium matrix, there was an increase in the surface area and a simultaneous reduction in the size of the aluminium matrix grains. Consequently, the hardness of the AA6063 composite also improved. The hard reinforcement of $\mathrm{Si}_{3} \mathrm{~N}_{4}$ having higher surface area particles reduces the possibility of plastic deformation which ultimately increases the hardness of powder metallurgy manufactured AMCs. Furthermore, because of the low ductile percentage of matrix metal in the composite, hard and brittle $\mathrm{Si}_{3} \mathrm{~N}_{4}$ particles in the soft and ductile AA6063 matrix diminishes the plasticity component of processed AMCs, which enhances the hardness of produced AMCs greatly. The alloy formation increases as the copper nitrate level rises, resulting in a continuous layer between the aluminum and the copper nitrate particles. Deformation turns out to be considerably more difficult, which results in higher hardness levels, as previously stated [30]. Increased reinforcement in the matrix generates an increase in dislocation density during the sintering process. The composite hardness has been increased due to a thermal mismatch between the aluminium matrix and the reinforcement. Furthermore, the temperature differential and the difference in thermal expansion between the two elements, such as aluminium matrix and reinforcement, are responsible for high hardness. Hence, the aluminium matrix deforms to encapsulate the smaller volume expansion in the plastic of $\mathrm{Si}_{3} \mathrm{~N}_{4}$ and $\mathrm{CuN}_{2} \mathrm{O}_{6}$ particles, creating tremendous internal stress. Hardness and restriction of plastic deformation increase due to better dislocation density at the particle-matrix interface. Sureshkumar et al. [31] reported an increase in the amount of reinforcement in the matrix the hardness of AMCs also increased.

\subsection{ANOVA and the effects of factors}


An analysis of variance (ANOVA) table 5 was developed to establish the order of essential components and their interactions. As well as the impact of several process parameters such as load, reinforcement $\left(\mathrm{Si}_{3} \mathrm{~N}_{4}+\mathrm{CuN}_{2} \mathrm{O}_{6}\right)$, sliding speed, and sliding distance. This study was conducted with a $5 \%$ level of confidence in the soundness of the outcomes. The wear characteristic of prepared composite of ANOVA is shown in Table. 5. Interaction between reinforcement and load ( $p=31.66 \%$ ), reinforcement and sliding distance, $\mathrm{CuN}_{2} \mathrm{O}_{6}$ reinforcement ( $\mathrm{p}=28.47 \%$ ) had a significant impact on wear loss is reported in Table. 5. The influences of sliding distance, load, and sliding velocity alone were less influential on wear loss, while the interactions between sliding speed and reinforcement did not affect the wear loss.

\subsection{The function of process parameters on wear loss}

Fig.7 shows the wear loss of the prepared composite affected by the process parameter. If a parameter's line in the main effect plot is close to horizontal, that parameter has no considerable influence. The parameter line has extreme inclination has the greatest impact. The process parameter of reinforcement had the most significant effect, according to the studies. Other testing variables, including load, sliding distance, and sliding speed, had a smaller impact. The relationship between the reinforcement and the load, on the other hand, has a great effect on wear loss. The sliding distance and load increase the wear loss due to higher material removed for the composite surface. Additionally, when the sliding speed rises, wear loss decreased owing to the development of a copper-rich passive deposit on the worn surfaces, which reduced wear by covering more contact area. Compared to other situations (i.e., $0 \%$ and $2 \%$ ), the composite with $4 \%$ reinforcement improved wear resistance at greater loads.

\subsection{Using the Taguchi method, analyze and evaluate the findings of the tests.}

The $\mathrm{S} / \mathrm{N}$ ratio is the most vital criterion in the Taguchi method for assessing experimental data portrayed in Fig. 8. The maximum $\mathrm{S} / \mathrm{N}$ ratio provided the optimal conditions of wear loss for this investigation. The wear loss of $\mathrm{S} / \mathrm{N}$ response for hybrid composites was reported in Table. 6. Delta statistics were used for the rank of influence of parameter impact on wear. The Delta statistic is the sum of each element's highest and lowest averages. The highest Delta value is assigned to rank 1 , the second-highest Delta value is assigned to rank 2, and so on. On an excellent wear resistance value, the optimal conditions were 4 wt. Percent $\mathrm{CuN}_{2} \mathrm{O}_{6}, 15 \mathrm{~N}_{\text {load, }}$ $200 \mathrm{rpm}$ sliding speed, and $2000 \mathrm{~m}$ sliding distance.

\subsection{Multilinear regression analysis and Confirmation test of experiment}

By fitting a linear equation to the observed data, this produced model provides the link between an indicator variable and a response variable. The wear rate regression equation is as follows:

Wear loss $=0.0066+0.00394^{\star} A+0.001617^{\star} B+0.000003^{*} C-0.000046^{\star} D-0.000508^{\star} A x$

$B-0.000002 * A \times C+$

$0.000013^{\star} \mathrm{A} \times \mathrm{D}$

Where, $\mathrm{A}=$ reinforcement, $\mathrm{B}=$ Load, $\mathrm{C}=$ Sliding distance, $\mathrm{D}=$ Sliding speed

Table 8 indicates the experimental values for conducting the dry sliding wear test \& adopting the best condition to compare the estimated wear result with the actual wear rate. According to the analysis, the actual wear rate differs from those calculated using regression equations, with error percentages ranging from $6.42 \%$ to $9.25 \%$ for wear rate according to the analysis [32].

\subsection{EDS analysis}

EDS analysis was performed on the worn surfaces of the PM-produced composite under dry sliding conditions. The presence of an oxygen peak in all EDS studies of the hybrid composites suggested that oxide formation of the worn surface occurred due to $\mathrm{CuN}_{2} \mathrm{O}_{6}$ inorganic reinforcement. While the composite is sliding on a steel counter surface, the combined action of temperature increase and environmental response can result in oxide layer deposition at the contact surfaces (EN31). Fig. 8 shows the EDS spectrum of the worn composite. The EDS of the worn surface discloses the existence of two-element peak intensities such as Al and Si. However, under dry sliding conditions, the Al intensity peak showed plastic deformation of the composite. Figure. 8 compared to the EDS profile of $A A 6063 / 12 \% \mathrm{Si}_{3} \mathrm{~N}_{4}$, worn surface, the acetone peak was observed. The intensity of acetone was increased as the $\mathrm{CuN}_{2} \mathrm{O}_{6}$ reinforcement increased. This acetone generated a protective oxide layer on the composite's surface. As inorganic reinforcement increases, the peak of Ac rises, reducing the wear rate. All fabricated composites had a carbon peak, which increased 
the work hardening rate of the composite, which increased abrasion resistance. Oxygen was noticed in all EDS spectrum due to the development of mated parts' worn surfaces.

\subsection{Wear surface studies}

The manufactured composites have fewer concentrations of carbon, silicon, and iron. Chemical reactions, such as oxidation, are stimulated by the limited heating created during the pin-on-disc test. A considerable difference was discovered after a wear study on $\mathrm{AA6063} / 12 \% \mathrm{Si}_{3} \mathrm{~N}_{4} / 2 \% \mathrm{CuN}_{2} \mathrm{O}_{6}$, with the main factor influencing wear was the formation of a generalized mechanically mixed layer (MML) seen in Fig. 9. This MML, which could contain iron and aluminium oxide, appears to be more resistant to temperature gradient without sticking. Furthermore, the hybrid composites have less plastic deformation, indicating a stronger resilience to wear, as seen by the hybrid composites' lower wear rate.

It is well known that increasing the amount of ceramic reinforcement $\mathrm{Si}_{3} \mathrm{~N}_{4}$ and inorganic copper nitrate particles in AA6063 treated by PM methods improves the tribological characteristics of the material, since $\mathrm{Si}_{3} \mathrm{~N}_{4}$ and copper nitrate particles protect the matrix from wear [30]. Furthermore, compared to ceramic reinforcement alone composites, the hybrid's greater wear resistance can be explained by thermal expansion matrix work hardening and dislocation strengthening [31].

Fig. 9 shows the worn microstructure of the AA6063 alloy reveals a large amount of Al alloy plastic deformation. The quantity of heat generated between the rolling pin's surface and the counter disk's surface, causing plastic deformation. It is discovered that the mode of wear is adhesive. The worn micrograph of the composite shows shallower grooves with fewer pits. The depth of the grooves is lowered due to the presence of $\mathrm{Si}_{3} \mathrm{~N}_{4}$ and inorganic reinforcement of $\mathrm{CuN}_{2} \mathrm{O}_{6}$ particles. Furthermore, the lesser degree of plastic deformation at the groove's borders is visible. The abrasive wear mechanism has been discovered.

\section{Conclusion}

The following are some of the most important findings from investigations on $\mathrm{AA6063} / \mathrm{Si}_{3} \mathrm{~N}_{4} \mathrm{CuN}_{2} \mathrm{O}_{6} \mathrm{MMCs}$ :

- $\mathrm{AA6063} / \mathrm{Si}_{3} \mathrm{~N}_{4} / \mathrm{CuN}_{2} \mathrm{O}_{6}$ MMCs were successfully fabricated with reinforcement content up to $12 \%$ of $\mathrm{Si}_{3} \mathrm{~N}_{4}$ and $4 \%$ of CuN $\mathrm{O}_{6}$ using powder metallurgical techniques (solid-state process). The MMCs' densities were higher than the base alloy. When $12 \mathrm{wt}$.\% $\mathrm{Si}_{3} \mathrm{~N}_{4}$ is added to a composite, the density increases by $2.47 \%$ compared to the base alloy. Further, density increases by $1.57 \%$ when $\mathrm{CuN}_{2} \mathrm{O}_{6}$ is added.

- The hardness of the composite increased about $74.72 \%$ with the addition of $12 \% \mathrm{Si}_{3} \mathrm{~N}_{4}$ and further increased $34.71 \%$ as $4 \%$ $\mathrm{CuN}_{2} \mathrm{O}_{6}$ addition compared to base alloy due to thermal expansion coefficient between AA6063 and $\mathrm{Si}_{3} \mathrm{~N}_{4}+\mathrm{CuN}_{2} \mathrm{O}_{6}$ reinforcement.

- The order of percentage of sliding distance, reinforcement, sliding speed, and load all influence the wear rate. According to ANOVA test results, as the reinforcement increases, the wear rate drops dramatically. The best conditions for wear rate were $12 \mathrm{wt} . \% \mathrm{Si}_{3} \mathrm{~N}_{4}$ and $4 \mathrm{wt} . \% \mathrm{CuN}_{2} \mathrm{O}_{6}$ reinforcement, $15 \mathrm{~N}$ applied load, $2000 \mathrm{~m}$ sliding distance, and $200 \mathrm{rpm}$ sliding speed, respectively. Among the wear factors, the percentage of reinforcement $(28.74 \%)$ has the most significant physical features and statistical influence on composites' dry sliding wear rate, compared to other parameters such as applied load (6.46\%) and sliding distance (4.13\%). Compared to other parameter interactions, the interaction between reinforcement and applied load (31.66\%) substantially impacted the manufactured composite's wear rate. The composite's worn micrograph exhibits shallower grooves and fewer pits. The inclusion of $\mathrm{Si}_{3} \mathrm{~N}_{4}$ and inorganic reinforcement of $\mathrm{CuN}_{2} \mathrm{O}_{6}$ particles reduces the depth of the grooves.

\section{Declarations}

\section{Conflict of Interest}

The manuscript was written through the contributions of all authors. All authors have approved the final version of the manuscript. The authors declare that they have no competing interests.

\section{Acknowledgments}

Page $7 / 21$ 
The authors are thankful to the Ramco Institute of Technology, Rajapalayam, Tamilnadu, India for providing facility to carry out this research work.

\section{References}

1. Bodukuri AK, Eswaraiah K, Rajendar K, Sampath V. Fabrication of Al-SiC-B4C metal matrix composite by powder metallurgy technique and evaluating mechanical properties. Perspect Sci 2016;8:428-31. https://doi.org/10.1016/j.pisc.2016.04.096.

2. Balasubramanian I, Maheswaran R. Effect of inclusion of SiC particulates on the mechanical resistance behaviour of stir-cast AA6063/SiC composites. Mater Des 2015;65:511-20. https://doi.org/10.1016/j.matdes.2014.09.067.

3. Toptan F, Kilicarslan A, Karaaslan A, Cigdem M, Kerti I. Processing and microstructural characterisation of AA 1070 and AA 6063 matrix B4Cp reinforced composites. Mater Des 2010;31:S87-91. https://doi.org/10.1016/j.matdes.2009.11.064.

4. Alizadeh A, Taheri-Nassaj E, Baharvandi HR. Preparation and investigation of Al-4 wt\% B4C nanocomposite powders using mechanical milling. Bull Mater Sci 2011;34:1039-48. https://doi.org/10.1007/s12034-011-0158-5.

5. Pournaderi S, Mahdavi S, Akhlaghi F. Fabrication of Al/Al 203 composites by in-situ powder metallurgy (IPM). Powder Technol 2012;229:276-84. https://doi.org/10.1016/j.powtec.2012.06.056.

6. Kanthavel K, Sumesh KR, Saravanakumar P. Study of tribological properties on Al/Al203/MoS2 hybrid composite processed by powder metallurgy. Alexandria Eng J 2016;55:13-7. https://doi.org/10.1016/j.aej.2016.01.024.

7. Cabeza M, Feijoo I, Merino P, Pena G, Pérez MC, Cruz S, et al. Effect of high energy ball milling on the morphology, microstructure and properties of nano-sized TiC particle- reinforced 6005A aluminium alloy matrix composite. Powder Technol 2017;321:3143. https://doi.org/10.1016/j.powtec.2017.07.089.

8. Ravi Kumar K, Kiran K, Sreebalaji VS. Micro structural characteristics and mechanical behaviour of aluminium matrix composites reinforced with titanium carbide. J Alloys Compd 2017;723:795-801.

https://doi.org/10.1016/j.jallcom.2017.06.309.

9. Ashok Kumar B, Murugan N. Metallurgical and mechanical characterization of stir cast AA6061-T6-AINp composite. Mater Des 2012;40:52-8. https://doi.org/10.1016/j.matdes.2012.03.038.

10. Mathan Kumar N, Senthil Kumaran S, Kumaraswamidhas LA. An investigation of mechanical properties and corrosion resistance of Al2618 alloy reinforced with Si3N4, AIN and ZrB2 composites. J Alloys Compd 2015;652:244-9. https://doi.org/10.1016/j.jallcom.2015.08.205.

11. Aravindan MK, Kulendran B, Murali G. Carbon - Science and Technology 2014.

12. Ramesh CS, Ahamed A, Channabasappa BH, Keshavamurthy R. Development of Al 6063-TiB2 in situ composites. Mater Des 2010;31:2230-6. https://doi.org/10.1016/j.matdes.2009.10.019.

13. Kumar GBV, Panigrahy PP, Nithika S, Pramod R, Rao CSP. Assessment of mechanical and tribological characteristics of Silicon Nitride reinforced aluminum metal matrix composites. Compos Part B Eng 2019;175:107138. https://doi.org/10.1016/j.compositesb.2019.107138.

14. Basavarajappa S, Chandramohan G, Mukund K, Ashwin M, Prabu M. Dry sliding wear behavior of Al 2219/SiCp-Gr hybrid metal matrix composites. J Mater Eng Perform 2006;15:668-74. https://doi.org/10.1361/105994906X150803.

15. Abdizadeh H, Ashuri M, Moghadam PT, Nouribahadory A, Baharvandi HR. Improvement in physical and mechanical properties of aluminum/zircon composites fabricated by powder metallurgy method. Mater Des 2011;32:4417-23. https://doi.org/10.1016/j.matdes.2011.03.071.

16. Meignanamoorthy M, Ravichandran M. Synthesis of metal matrix composites via powder metallurgy route: A review. Mech Mech Eng 2018;22:65-75. https://doi.org/10.2478/mme-2018-0007.

17. Fathy A, El-Kady O, Mohammed MMM. Effect of iron addition on microstructure, mechanical and magnetic properties of Almatrix composite produced by powder metallurgy route. Trans Nonferrous Met Soc China (English Ed 2015;25:46-53. https://doi.org/10.1016/S1003-6326(15)63577-4.

18. Rahimian M, Parvin N, Ehsani N. The effect of production parameters on microstructure and wear resistance of powder metallurgy Al-Al2O3 composite. Mater Des 2011;32:1031-8. https://doi.org/10.1016/j.matdes.2010.07.016. 
19. Pal MK, Sandhu SS, Kalia R, Ghosh A. Identification of Optimum Composition and Mechanical Properties of Al-Ni Metal Matrix Composite. J Miner Mater Charact Eng 2015;03:326-34. https://doi.org/10.4236/jmmce.2015.34035.

20. Raj N, Radhika N. Tribological Characteristics of LM13/Si 3 N 4 /Gr Hybrid Composite at Elevated Temperature. Silicon 2019;11:947-60. https://doi.org/10.1007/s12633-018-9893-1.

21. Lotfy A, Pozdniakov A V., Zolotorevskiy VS, Abou El-khair MT, Daoud A, Mochugovskiy AG. Novel preparation of Al-5\%Cu / BN and Si3N4 composites with analyzing microstructure, thermal and mechanical properties. Mater Charact 2018;136:144-51. https://doi.org/10.1016/j.matchar.2017.12.015.

22. Sharma P, Sharma S, Khanduja D. Production and some properties of Si $3 \mathrm{~N} 4$ reinforced aluminium alloy composites. J Asian Ceram Soc 2015;3:352-9. https://doi.org/10.1016/j.jascer.2015.07.002.

23. Uvaraja VC, Natarajan N. Optimization of Friction and Wear Behaviour in Hybrid Metal Matrix Composites Using Taguchi Technique. J Miner Mater Charact Eng 2012;11:757- 68. https://doi.org/10.4236/jmmce.2012.118063.

24. Ghosh S, Sahoo P, Sutradhar G. Wear Behaviour of Al-SiCp Metal Matrix Composites and Optimization Using Taguchi Method and Grey Relational Analysis. J Miner Mater Charact Eng 2012;11:1085-94. https://doi.org/10.4236/jmmce.2012.1111115.

25. Asha PB, Murthy SS, Rao CRP, Kumar VR, Kiran R, Suresha CN. Optimization of Wear Factors of Aluminium Hybrid Metal Matrix Composites Using Taguchi Method. J Miner Mater Charact Eng 2021;09:38-47. https://doi.org/10.4236/jmmce.2021.91003.

26. Allahham MS, Al-Sa'd MF, Al-Ali A, Mohamed A, Khattab T, Erbad A. DroneRF dataset: A dataset of drones for RF-based detection, classification and identification. Data $\mathrm{Br}$ 2019;26:104313. https://doi.org/10.1016/j.dib.2019.104313.

27. Chauhan SR, Kumar A, Singh I, Kumar P. Effect of Fly Ash Content on Friction and Dry Sliding Wear Behavior of Glass Fiber Reinforced Polymer Composites - A Taguchi Approach. J Miner Mater Charact Eng 2010;09:365-87. https://doi.org/10.4236/jmmce.2010.94027.

28. Mishra AK, Kumar V, Srivastava RK. Optimization of Tribological Performance of Al- 6061 T6-15\% SiCp-15\% Al\&lt;sub\&gt;2\&lt;/sub\&gt;O\&lt;sub\&gt;3\&lt;/sub\&gt; Hybrid Metal Matrix Composites Using Taguchi Method \&amp; Grey Relational Analysis. J Miner Mater Charact Eng 2014;02:351-61. https://doi.org/10.4236/jmmce.2014.24040.

29. Rajmohan T, Palanikumar K, Arumugam S. Synthesis and characterization of sintered hybrid aluminium matrix composites reinforced with nanocopper oxide particles and microsilicon carbide particles. Compos Part B Eng 2014;59:43-9. https://doi.org/10.1016/j.compositesb.2013.10.060.

30. Madhusudan S, Sarcar MMM, Rao NBRM. Mechanical properties of Aluminum-Copper(p) composite metallic materials. J Appl Res Technol 2016;14:293-9. https://doi.org/10.1016/j.jart.2016.05.009.

31. Sureshkumar P, Uvaraja VC. Effect of ceramic and metallic reinforcement on mechanical, corrosion, and tribological behavior of aluminum composite by adopting design of experiment through Taguchi technique. J Tribol 2018;140:1-12. https://doi.org/10.1115/1.4039527.

32. Miranda G, Buciumeanu M, Madeira S, Carvalho O, Soares D, Silva FS. Hybrid composites - Metallic and ceramic reinforcements influence on mechanical and wear behavior. Compos Part B Eng 2015;74:153-65.

https://doi.org/10.1016/j.compositesb.2015.01.007.

\section{Tables}

Table. 1 Chemical composition of AA6063

\begin{tabular}{llllllllll} 
Element & $\mathrm{Si}$ & $\mathrm{Mg}$ & $\mathrm{Fe}$ & $\mathrm{Mn}$ & $\mathrm{Cu}$ & $\mathrm{Zn}$ & $\mathrm{Cr}$ & $\mathrm{Ti}$ & $\mathrm{Al}$ \\
\hline Content \% & 0.48 & 0.47 & 0.34 & 0.1 & 0.1 & 0.1 & 0.08 & 0.05 & Balance
\end{tabular}

Table. 2 The composites used for this study 


\begin{tabular}{ll}
\hline S.No. & Specimen compositions \\
\hline 1. & AA6063/6\% $\% \mathrm{Si}_{3} \mathrm{~N}_{4}$ \\
2. & AA6063/12\% $\mathrm{Si}_{3} \mathrm{~N}_{4}$ \\
3. & AA6063/12\% $\% \mathrm{Si}_{3} \mathrm{~N}_{4} / 2 \% \mathrm{CuN}_{2} \mathrm{O}_{6}$ \\
4. & AA6063/12\% $\mathrm{Si}_{3} \mathrm{~N}_{4} / 4 \% \mathrm{CuN}_{2} \mathrm{O}_{6}$ \\
\hline
\end{tabular}

Table. 3 Various Levels of Process Parameters

\begin{tabular}{lllll} 
Variable & Units & Level I & Level II & Level III \\
\hline $\begin{array}{l}\text { Si3N4 +CuN2O6 } \\
\text { reinforcement }\end{array}$ & wt.\% & $6+0$ & $12+0$ & $12+4$ \\
\hline Load & N & 10 & 15 & 20 \\
\hline Sliding Distance & m & 1000 & 1500 & 2000 \\
\hline Sliding Speed & rpm & 200 & 300 & 400
\end{tabular}

Table. 4 L27 orthogonal matrix Taguchi Design 


\begin{tabular}{|c|c|c|c|c|c|c|c|}
\hline L27 (213) & wt. \%of reinforcement & Load & Sliding distance & Sliding Speed & Wear Loss & $\mathrm{S} / \mathrm{N}$ ratio & Mean \\
\hline 1. & $6 \%$ Si3N4 & 10 & 1000 & 200 & 0.018 & 34.8945 & 0.018 \\
\hline 2. & $6 \%$ Si3N4 & 10 & 1500 & 300 & 0.010 & 40.0000 & 0.010 \\
\hline 3. & $6 \%$ Si3N4 & 10 & 2000 & 400 & 0.009 & 40.9151 & 0.009 \\
\hline 4. & $6 \%$ Si3N4 & 15 & 1000 & 300 & 0.006 & 44.4370 & 0.006 \\
\hline 5. & $6 \%$ Si3N4 & 15 & 1500 & 400 & 0.009 & 40.9151 & 0.009 \\
\hline 6. & $6 \%$ Si3N4 & 15 & 2000 & 200 & 0.019 & 34.4249 & 0.019 \\
\hline 7. & $6 \%$ Si3N4 & 20 & 1000 & 400 & 0.030 & 30.4576 & 0.030 \\
\hline 8. & $6 \%$ Si3N4 & 20 & 1500 & 200 & 0.040 & 27.9588 & 0.040 \\
\hline 9. & $6 \%$ Si3N4 & 20 & 2000 & 300 & 0.035 & 29.1186 & 0.035 \\
\hline 10. & $12 \%$ Si3N4 & 10 & 1000 & 200 & 0.024 & 32.3958 & 0.024 \\
\hline 11. & $12 \%$ Si3N4 & 10 & 1500 & 300 & 0.015 & 36.4782 & 0.015 \\
\hline 12. & $12 \%$ Si3N4 & 10 & 2000 & 400 & 0.025 & 32.0412 & 0.025 \\
\hline 13. & $12 \%$ Si3N4 & 15 & 1000 & 300 & 0.035 & 29.1186 & 0.035 \\
\hline 14. & $12 \%$ Si3N4 & 15 & 1500 & 400 & 0.005 & 46.0206 & 0.005 \\
\hline 15. & $12 \%$ Si3N4 & 15 & 2000 & 200 & 0.026 & 31.7005 & 0.026 \\
\hline 16. & $12 \%$ Si3N4 & 20 & 1000 & 400 & 0.017 & 35.3910 & 0.017 \\
\hline 17. & $12 \%$ Si3N4 & 20 & 1500 & 200 & 0.006 & 44.4370 & 0.006 \\
\hline 18. & $12 \%$ Si3N4 & 20 & 2000 & 300 & 0.020 & 33.9794 & 0.020 \\
\hline \multirow[t]{2}{*}{19.} & $12 \%$ Si3N4 + & 10 & 1000 & 200 & 0.010 & 40.0000 & 0.010 \\
\hline & 4\% CuN2O6 & & & & & & \\
\hline \multirow[t]{2}{*}{20.} & $12 \%$ Si3N4 + & 10 & 1500 & 300 & 0.005 & 46.0206 & 0.005 \\
\hline & $4 \%$ CuN2O6 & & & & & & \\
\hline \multirow[t]{2}{*}{21.} & $12 \%$ Si3N4 + & 10 & 2000 & 400 & 0.004 & 47.9588 & 0.004 \\
\hline & $4 \%$ CuN2O6 & & & & & & \\
\hline \multirow[t]{2}{*}{22.} & $12 \%$ Si3N4 + & 15 & 1000 & 300 & 0.008 & 41.9382 & 0.008 \\
\hline & $4 \%$ CuN2O6 & & & & & & \\
\hline \multirow[t]{2}{*}{23.} & $12 \%$ Si3N4 + & 15 & 1500 & 400 & 0.010 & 40.0000 & 0.010 \\
\hline & $4 \%$ CuN2O6 & & & & & & \\
\hline \multirow[t]{2}{*}{24.} & $12 \%$ Si3N4 + & 15 & 2000 & 200 & 0.003 & 50.4576 & 0.003 \\
\hline & $4 \%$ CuN2O6 & & & & & & \\
\hline \multirow[t]{2}{*}{25.} & $12 \%$ Si3N4 + & 20 & 1000 & 400 & 0.011 & 39.1721 & 0.011 \\
\hline & $4 \%$ CuN2O6 & & & & & & \\
\hline \multirow[t]{2}{*}{26.} & $12 \%$ Si3N4 + & 20 & 1500 & 200 & 0.010 & 40.0000 & 0.010 \\
\hline & 4\% CuN2O6 & & & & & & \\
\hline \multirow[t]{2}{*}{27.} & $12 \%$ Si3N4 + & 20 & 2000 & 300 & 0.005 & 46.0206 & 0.005 \\
\hline & $4 \%$ CuN2O6 & & & & & & \\
\hline
\end{tabular}


Table. 5 Analysis of Variance for wear loss

\begin{tabular}{|c|c|c|c|c|c|c|}
\hline Source & DF & $\begin{array}{l}\text { Adjusted Sum } \\
\text { of Square }\end{array}$ & Adjusted Mean Square & $\begin{array}{l}\text { F- } \\
\text { Value }\end{array}$ & $\begin{array}{l}\text { P- } \\
\text { Value }\end{array}$ & Percentage of Contribution \\
\hline Wt.\% & 2 & 0.000873 & 0.000436 & 41.92 & 0.000 & 28.74 \\
\hline \multicolumn{7}{|l|}{ Reinforcement } \\
\hline Load & 2 & 0.000212 & 0.000106 & 10.19 & 0.012 & 6.46 \\
\hline Sliding distance & 2 & 0.000143 & 0.000072 & 6.88 & 0.028 & 4.13 \\
\hline Sliding Speed & 2 & 0.000072 & 0.000036 & 3.46 & 0.100 & 1.73 \\
\hline Wt.\% & 4 & 0.000980 & 0.000245 & 23.53 & 0.001 & 31.66 \\
\hline \multicolumn{7}{|c|}{ Reinforcement x Load } \\
\hline \multicolumn{7}{|l|}{ Wt.\% } \\
\hline & 4 & 0.000429 & 0.000107 & 10.30 & 0.007 & 13.08 \\
\hline \multicolumn{7}{|l|}{ Reinforcement $x$} \\
\hline \multicolumn{7}{|c|}{ Sliding distance Wt.\% } \\
\hline & 4 & 0.000196 & 0.000049 & 4.70 & 0.046 & 5.23 \\
\hline
\end{tabular}

Reinforcement $x$ Sliding Speed

Error

\begin{tabular}{lllll} 
& 6 & 0.000062 & 0.000010 & 8.95 \\
\hline Total & 26 & 0.002966 & & 100
\end{tabular}

$S=0.0032261, R-S q=97.82 \%$ and $R-S q(\operatorname{adj})=90.88 \%$

\section{Figures}



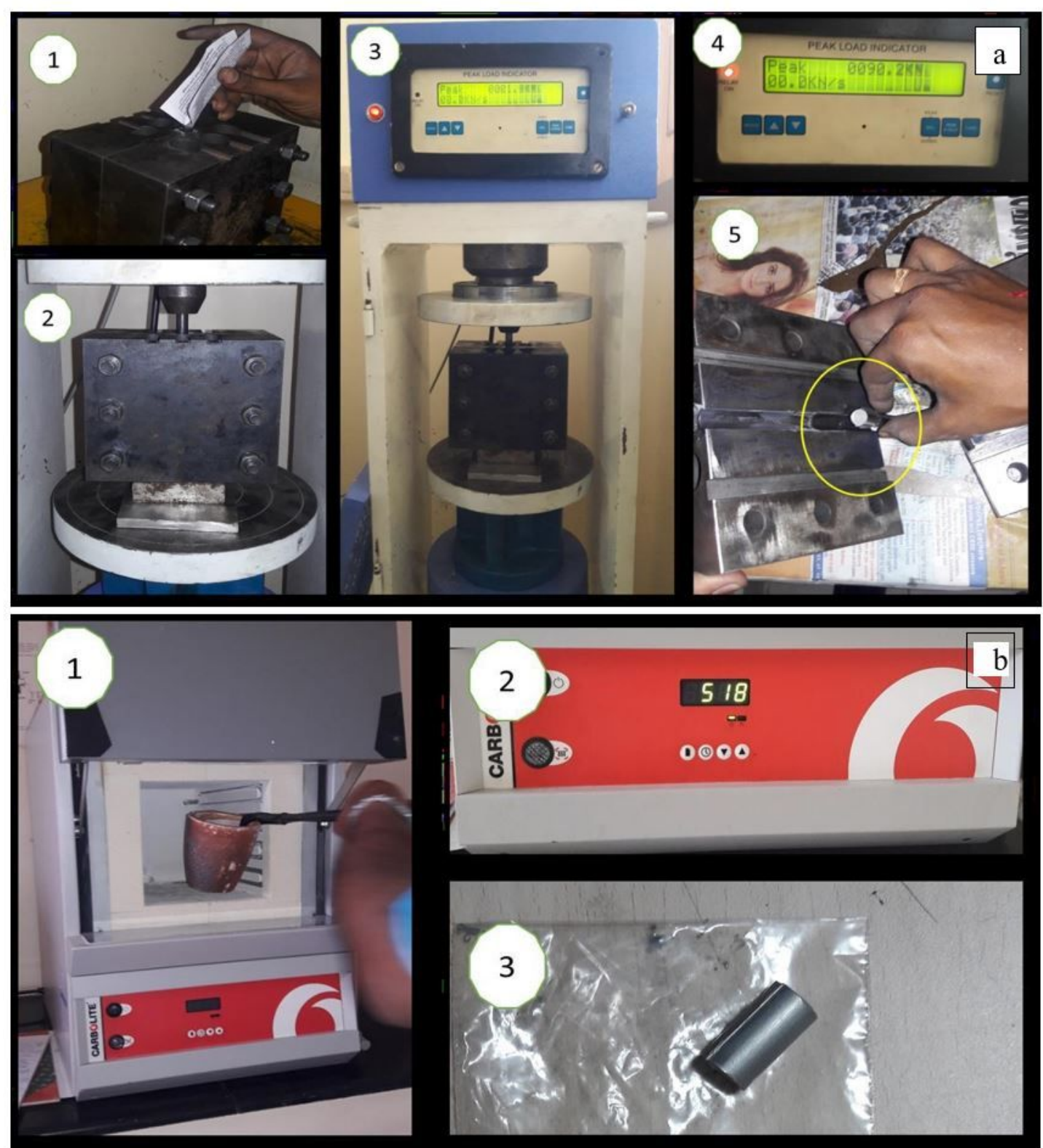

Figure 1

(a) Specimen Preparation (1) Filling Powder in the die assembly (2) Placing die in the CTM seating with Plunger (3) CTM Setup (4) Peak Load Indicator (5) Green Compact.

(b) Sintering Process (1) Placing Crucible inside the Furnace (2) Holding Temperature (3) Sintered Specimen. 


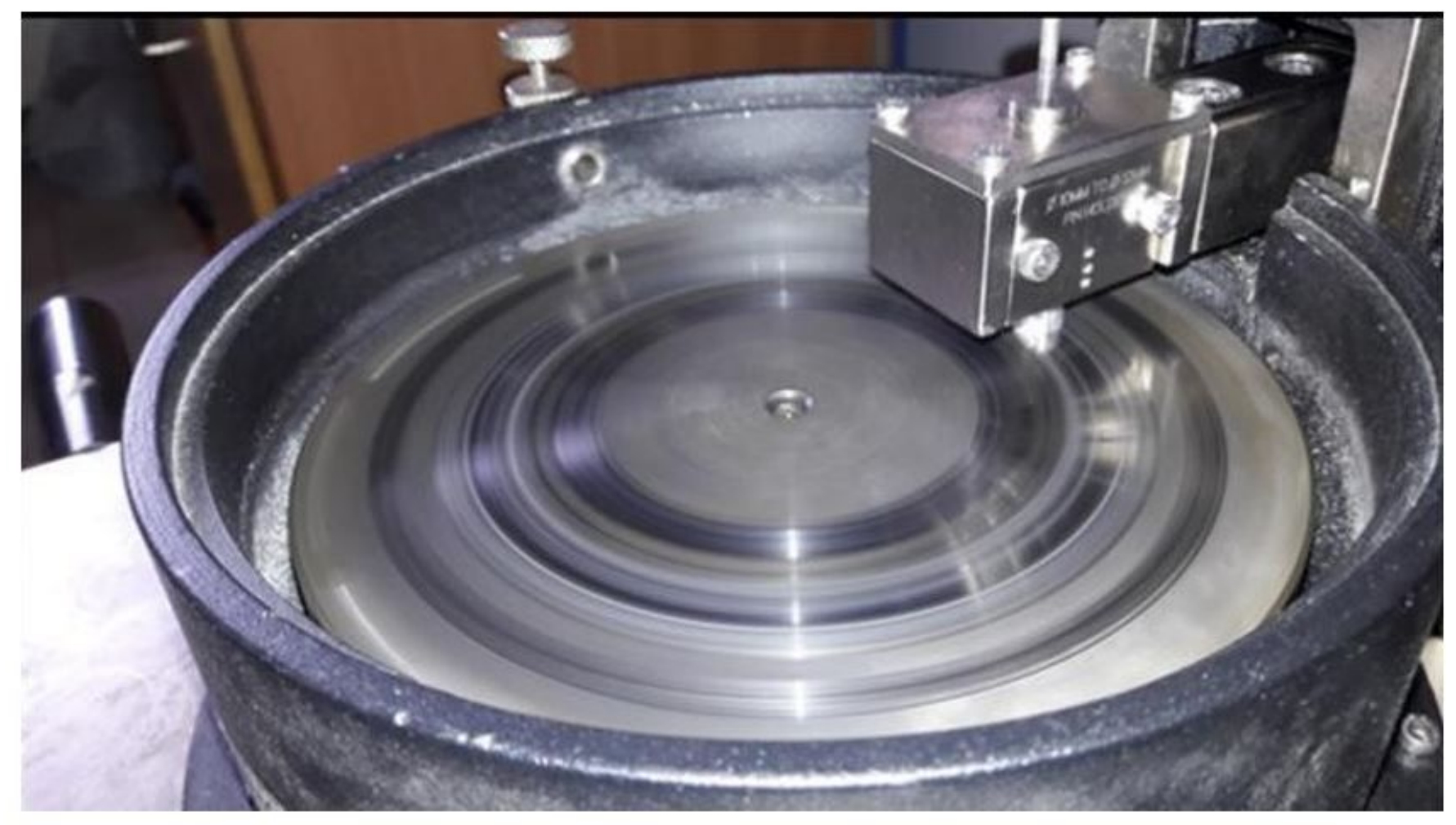

Figure 2

Pin-on-disc wear testing setup 


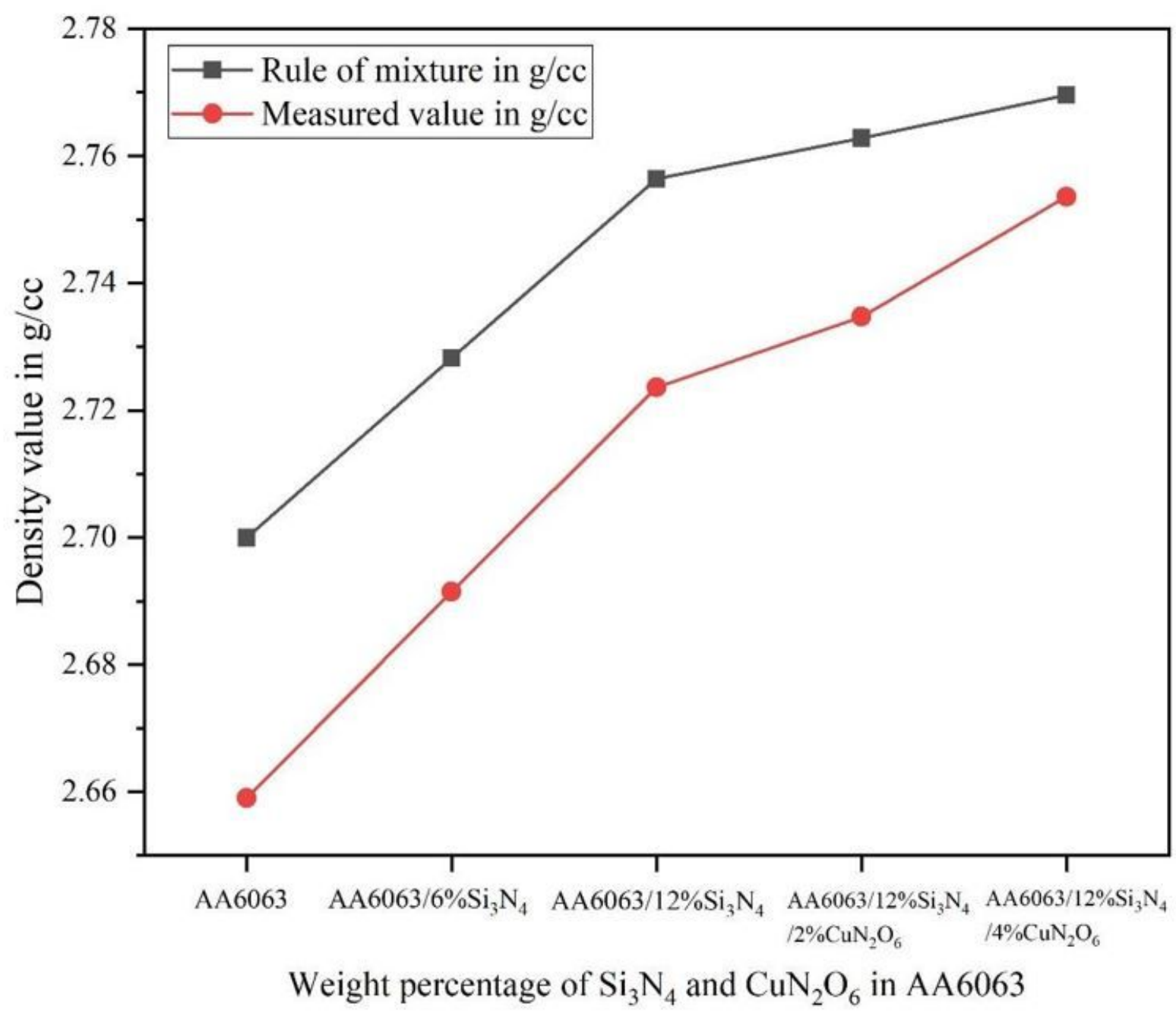

Figure 3

Density graph for the prepared composites 

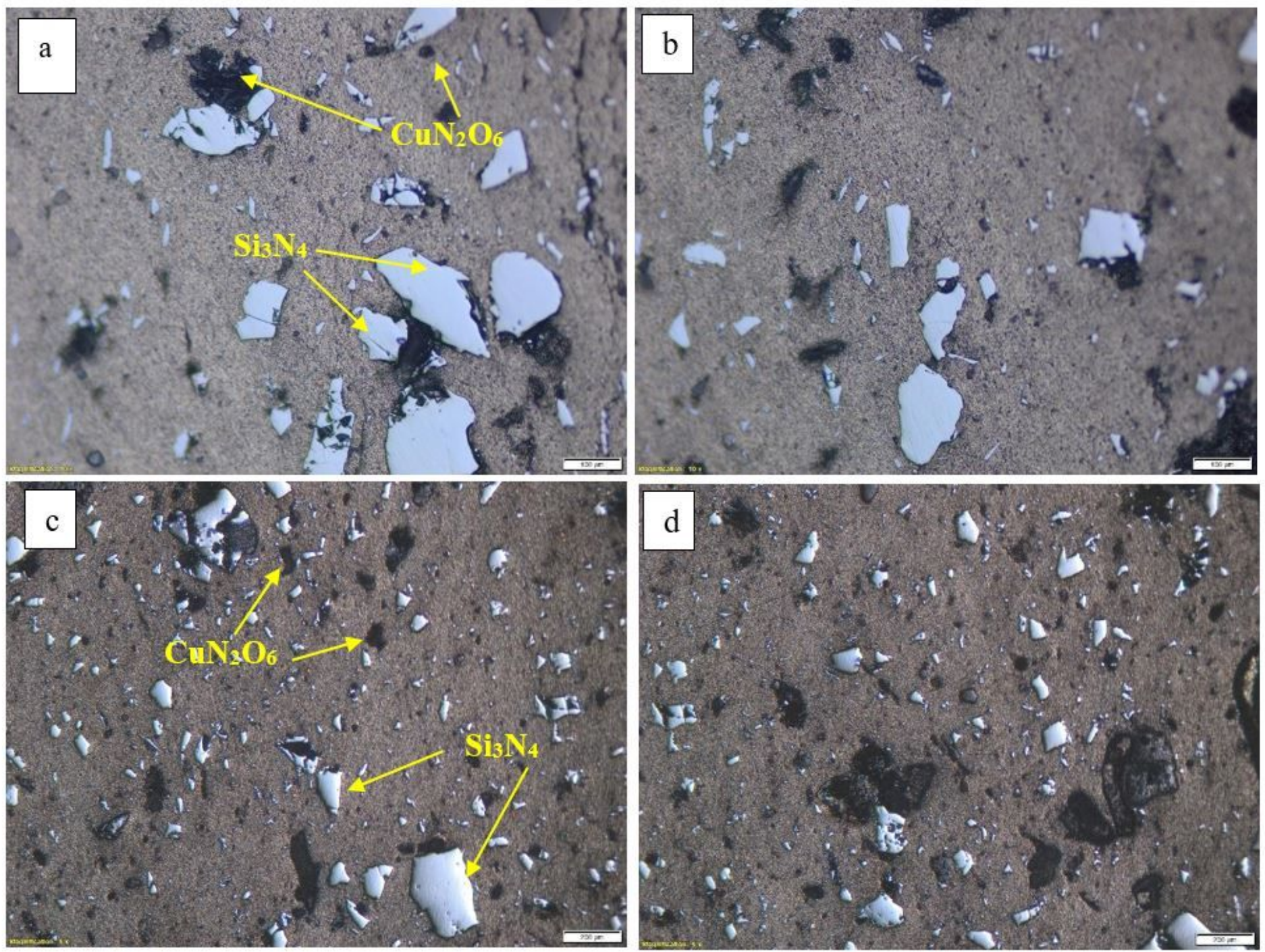

Figure 4

Optical microstructure of the PM produced composites. (a and b) AA 6063-12\%Si3N4- 2\%CuN2O6 and (c and d) AA 6063-12\%Si3N44\%CuN2O6 


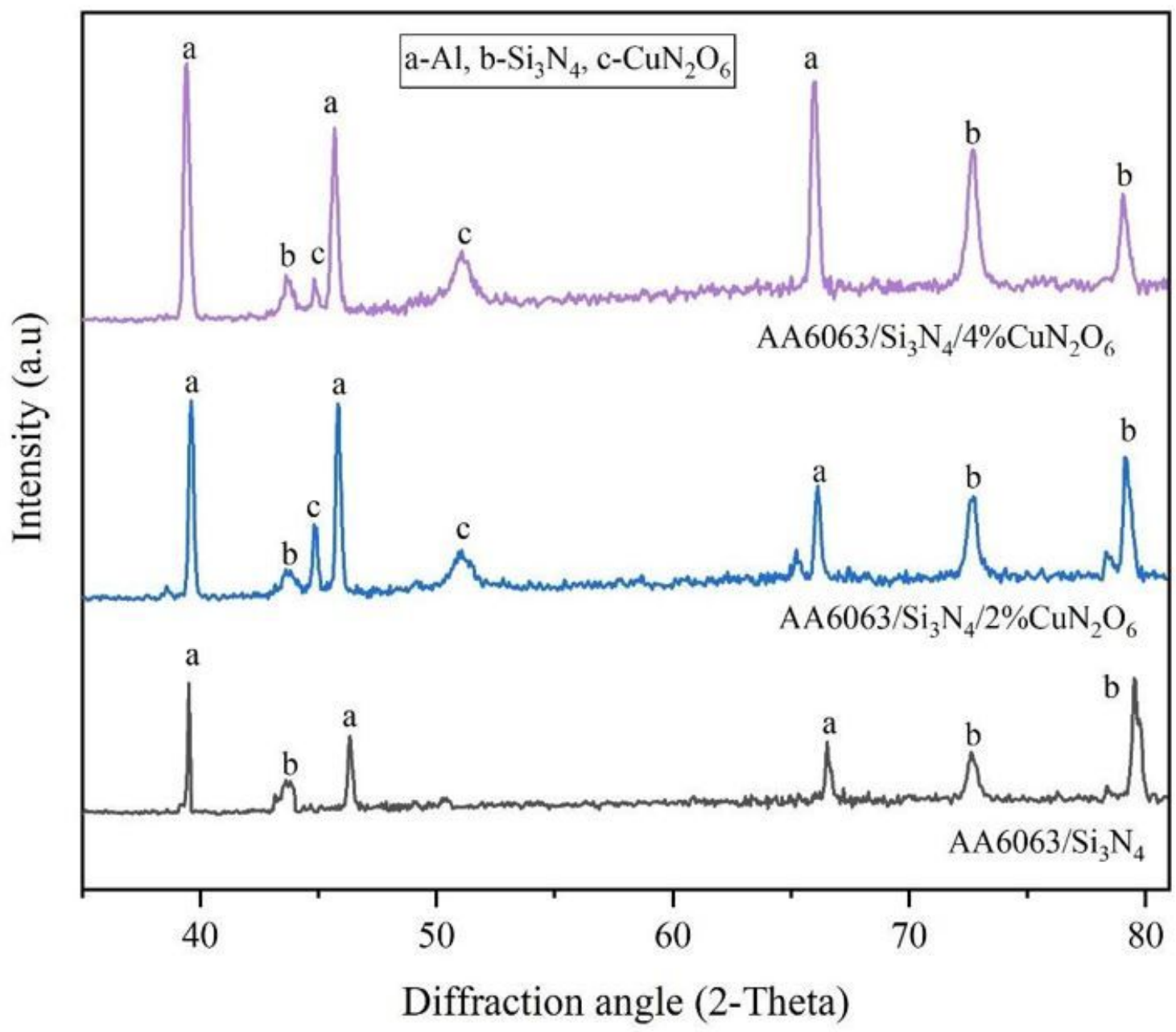

Figure 5

XRD pattern of the PM fabricated composites 


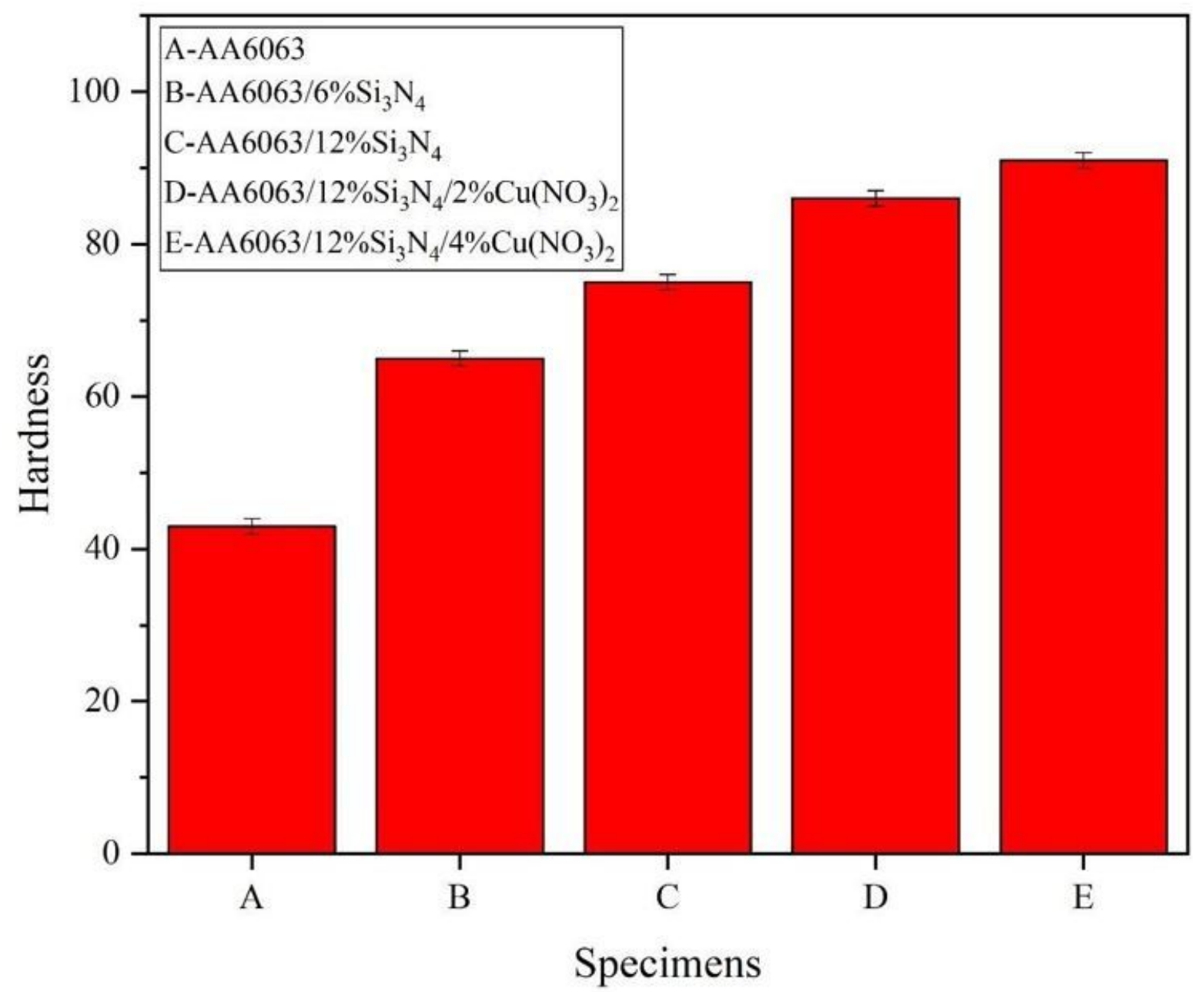

Figure 6

Hardness plot of the composites 

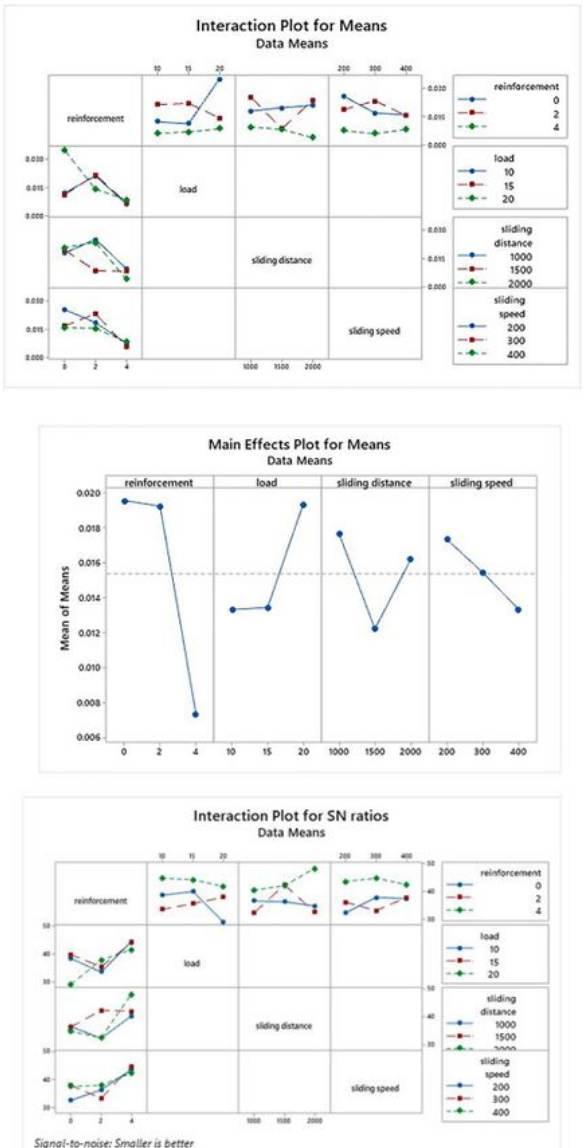

Signol-to-mosie: Smalter is better

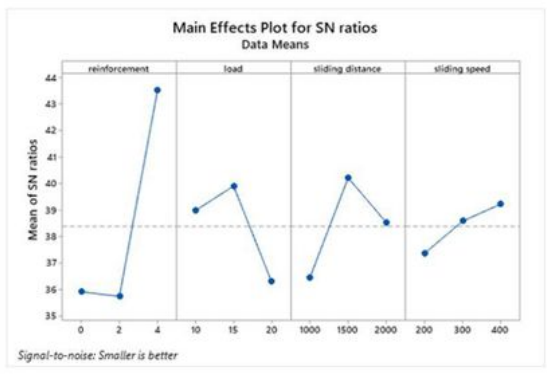

Figure 7

Influence of process parameters on wear loss 


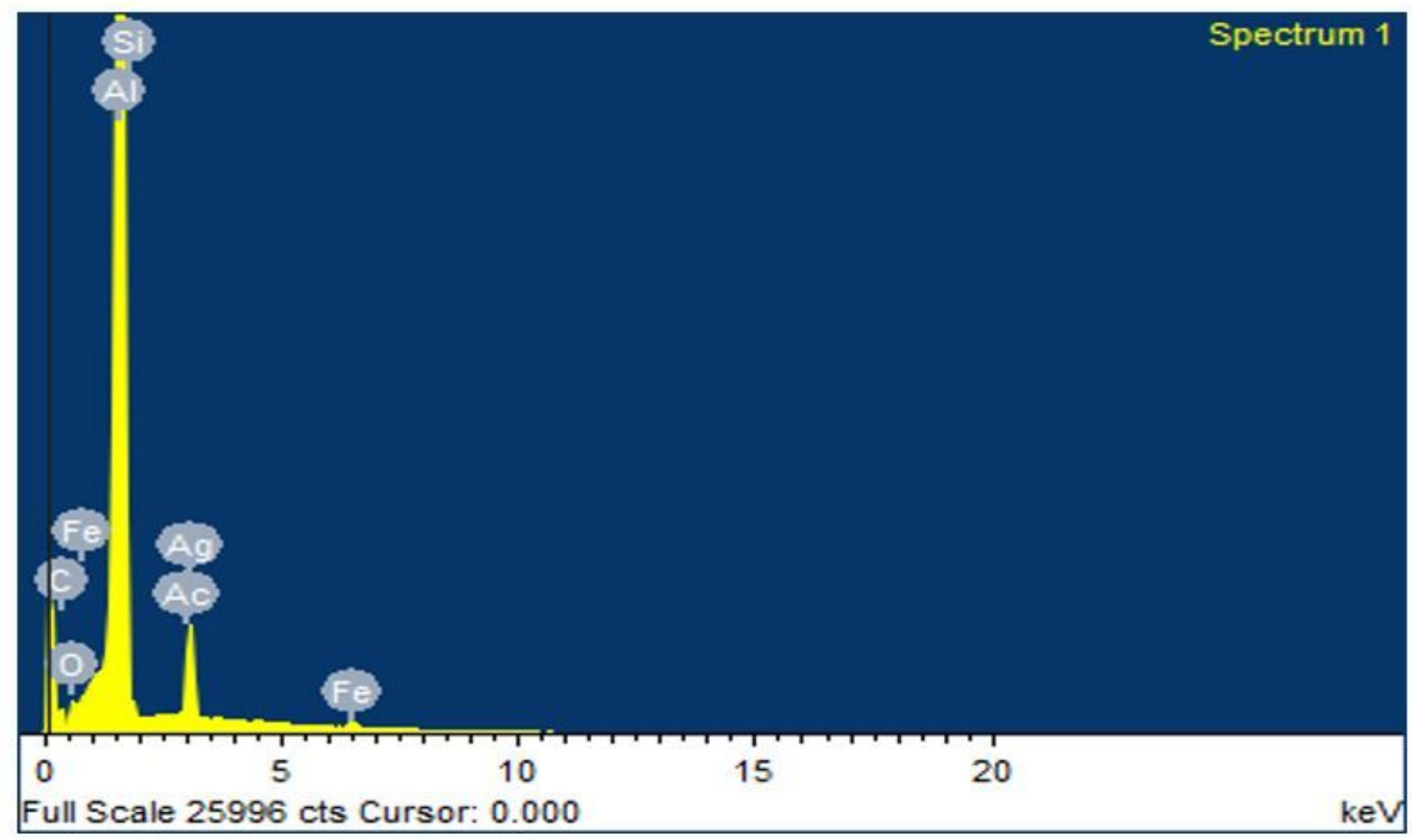

Figure 8

EDS analysis on the worn surface 

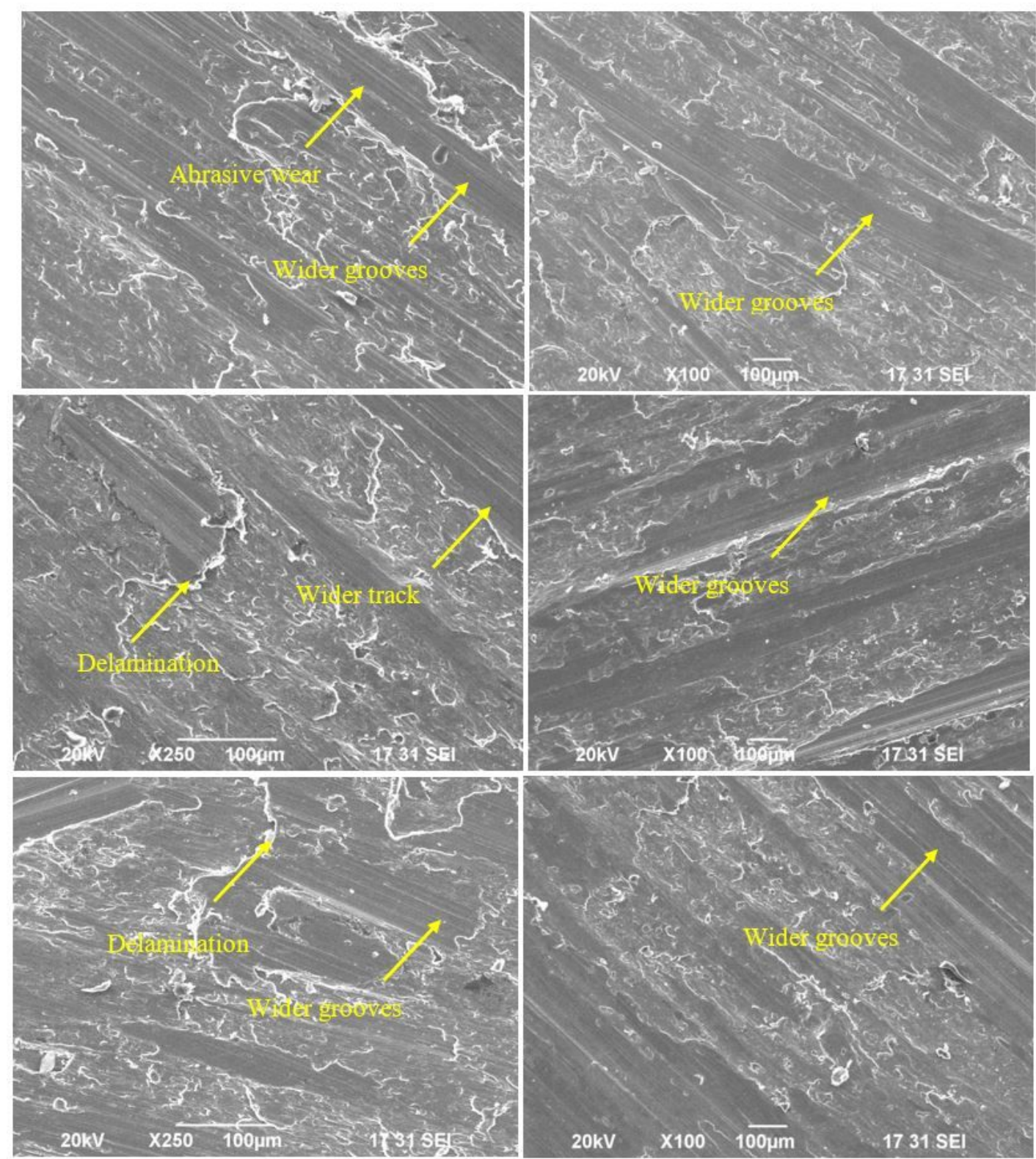

Figure 9

SEM wear track analysis of the composites 